\title{
EDUCAÇÃO INTEGRAL NO ENSINO SUPERIOR: UM OLHAR SOBRE O ASPECTO FÍSICO
}

\author{
EDUCACIÓN INTEGRAL EN LA ENSEÑANZA SUPERIOR: \\ UNA MIRADA SOBRE EL ASPECTO FÍSICO
}

\author{
INTEGRAL EDUCATION IN HIGHER EDUCATION: \\ A LOOK AT THE PHYSICAL ASPECT
}

\author{
Erling Walter Quiaper SIMEON ${ }^{1}$ \\ Helena Brandão VIANA ${ }^{2}$
}

\begin{abstract}
RESUMO: O presente artigo busca analisar as matrizes curriculares de uma instituição de ensino superior para verificar o aspecto do desenvolvimento físico presente como parte de uma educação integral proposta. Foi feito um levantamento bibliográfico da definição de educação integral, em seguida é apresentada a história da disciplina de educação física no currículo do ensino superior brasileiro. A análise da matriz apontou que a instituição possuía uma disciplina de educação física, que era prática e com diversidade de ambientes, mas após a LDB de 1996 e a ausência da obrigatoriedade dessa disciplina no ensino superior fez com que aos poucos ela fosse sendo substituída na matriz, deixando os alunos sem uma disciplina que cuide do desenvolvimento físico de forma prática.
\end{abstract}

PALAVRA-CHAVE: Educação integral. Desenvolvimento físico. Educação.

RESUMEN: El presente artículo busca analizar las matrices curriculares de una institución de enseñanza superior para verificar el aspecto del desarrollo físico presente como parte de una educación integral propuesta. Se realizo un levantamiento bibliográfico de la definición de educación integral, después fue apresentado la historia de la disciplina de educación física en el currículo de la enseñanza superior brasileña. El análisis de la matriz apuntó que la institución poseía una disciplina de educación física, que era práctica y con diversidade de ambientes, pero después de la LDB de 1996 y la ausência de la obligatoriedad de esa disciplina en la enseñanza superior hizo que poco a poco se substituyera de la matriz dejando a los alunos sin una disciplina que cuide el desarrollo físico de forma práctica.

PALABRAS CLAVE: Educación integral. Desarollo físico. Educación.

\footnotetext{
${ }^{1}$ Centro Universitário Adventista de São Paulo (UNASP), Engenheiro Coelho, - SP - Brasil. coordenador do PROAD EAD, professor regente das disciplinas de Cosmovisão Bíblico Cristã e Antropologia Cristã e é coordenador da produção das disciplinas religiosas da instituição. Tem experiência na área de Educação, EaD e projetos esportivos. OrcID: https://orcid.org/0000-0002-1089-7013. E-mail: walter.simeon@unasp.edu.br ${ }^{2}$ Centro Universitário Adventista de São Paulo (UNASP), Engenheiro Coelho, - SP - Brasil. Docente em cursos de pós-graduação no Unasp-HT. Professora permanente no mestrado em educação. OrcID: https://orcid.org/0000-0002-2018-202X. E-mail: hbviana2@gmail.com
} 
ABSTRACT: This article aims to analyze the curricular matrices of an institution of higher education to verify the aspect of the present physical development as part of a proposed integral education. A bibliographical survey of the definition of integral education was made, then, the history of the discipline of physical education in the Brazilian higher education curriculum was presented. The analysis of the matrix pointed out that the institution had a physical education discipline, which was practical and with a diversity of environments, but after the LDB of 1996 and the absence of compulsory discipline in higher education, it was gradually replaced in the matrix leaving students without a discipline that takes care of physical development in a practical way.

KEYWORDS: Integral education. Physical Development. Education.

\section{Introdução}

Educação integral significa uma educação completa do ser humano; esse é um conceito antigo que vem desde os tempos de Aristóteles, discípulo de Platão, que via a PAIDEIA como uma educação plena e integral do homem, envolvendo o desenvolvimento subjetivo e social do indivíduo, abrangendo nessa formação questões como ética e identidade política. Na Grécia antiga os educadores e filósofos exerciam papel ativo na execução da PAIDEIA grega, onde por meio de uma ação educadora buscavam a formação integral do homem, para que ele fosse alguém virtuoso, ético e livre. (BORTOLINI; NUNES, 2018).

Similar ao conceito de educação integral grega, Yus (2002) apresenta o conceito de educação holística do indivíduo:

São consideradas todas as facetas da experiência humana, não só o intelecto racional e as responsabilidades de vocação e cidadania, mas também os aspectos físicos, emocionais, sociais, estéticos, criativos, intuitivos e espirituais inatos da natureza do ser humano. (YUS, 2002, p. 16).

Da forma como Yus (2002) descreveu, a educação holística busca ações para uma educação mais completa, não meramente intelectual, percebendo o aluno como um ser a ser desenvolvido no seu todo. Nascimento e Souza (2014) apontam que os argumentos do início dos estudos por uma educação holística tinham que ver com um melhor entendimento de quem é o aluno e a melhora nos relacionamentos, mas que atualmente a educação holística está mais relacionada com o conceito de qualidade de vida para o alcance dessas melhorias para todos.

Rousseau, pensador europeu no período do iluminismo do século XVIII, recebeu uma forte influência da mudança social de sua época com o rápido crescimento industrial, aumento populacional das cidades e mudanças de valores sociais. Em sua proposta educacional, este 
buscava a harmonia entre o desenvolvimento sensorial, mental e moral do ser humano. (LORENZON; JORGE, 2011). Para Rousseau, como explicitado em sua obra Emílio, o aluno passa por três fases: a infância, até os 12 anos, com liberdade, mas sem permitir que afete a moralidade da criança com vícios, a adolescência, até os 15 anos, quando o aluno deve ser orientado em uma profissão, com um método racional e social, e a dos 15 aos 20, conhecida como "idade das razões e das paixões", é quando o homem nasce para a sociedade e deve ser desenvolvido no ponto de vista moral, jurídico e político.

Para Nascimento e Souza (2014), é importante que o professor que deseja trabalhar de forma plena os seus alunos seja formado dentro de novos paradigmas, para que ele consiga planejar ações pedagógicas que possam ajudar seus alunos a alcançar o tipo de homem e de sociedade transformadores. O ideal seria formar um indivíduo pleno, pronto para agir de forma que transforme positivamente a sociedade.

No final do século XIX e início do século XX, surge na França Henri Wallon, graduado em filosofia, medicina e especializado em psiquiatria, respeitado na área da psicologia infantil e consequentemente na pedagogia. Para Wallon, segundo GratiotAlfandéry (2010), o primeiro grau de ensino deveria ir dos 7 aos 18 anos, com 3 ciclos, 7 aos 11, 12 aos 15 e 16 aos 18, sendo preparados em cada ciclo para a formação como profissional, com testes próprios para as diferentes áreas em uma etapa de pré-terceiro grau, quando o aluno poderia ser encaminhado para as fábricas, se tivesse facilidade com os materiais, ou para a academia, se tivesse facilidade para os estudos. Nessa perspectiva, não só os alunos, mas os professores precisariam ter uma formação completa passando por três áreas, chamadas de ENS (Escola Normal Superior), promovendo educação pedagógica, técnica e de educação física. Os estudos de Wallon ligados à psicogenética estavam ligados ao desenvolvimento completo do aluno, indo além do intelecto. Ele não era favorável a uma educação que privilegiasse um único aspecto do desenvolvimento da criança, sendo seus temas centrais a emoção, movimento, inteligência e a personalidade. Gratiot-Alfandéry (2010) afirma que, na verdade, a teoria psicogenética de Wallon era uma junção da afetividade e da inteligência, formando assim uma educação plena do aluno.

No Brasil, o sistema educacional parece ter excluído mais os alunos do que agregado, em especial nas décadas de 70, 80 e 90. É o que afirma Cavaliere (2002), que apresenta um país ainda carente de uma política educacional efetiva, que cative e mantenha as crianças e adolescentes na escola. Anísio Teixeira ${ }^{3}$, influenciado pelas ideias do filósofo americano John

${ }^{3}$ Ao realizar seu curso de Mestrado na Universidade de Columbia, nos Estados Unidos, Anísio Teixeira tomou contato com as obras de John Dewey e W. H. Kilpatrick, que influenciaram sua formação e lhe deram as bases 
Dewey, adaptou a ideia da educação integral para a realidade brasileira na primeira metade do século XX. (CAVALIERE, 2002).

\section{História da educação física no currículo brasileiro}

Quando a história da educação física é revisada como parte do conteúdo proposto na educação formal brasileira, há detalhes importantes de um passado com atividades ligadas ao movimento do corpo. Os jesuítas, no período de 1559-1759, envolvendo atividades como a peteca, arco e flecha e outras atividades recreativas como parte da educação dos nativos brasileiros. Oliveira (2004) comenta que o Brasil era uma colônia de exploração, então os avanços em diversas áreas, incluindo a educação, não eram muito expressivos. O cenário educacional brasileiro só iria começar a mudar com a vinda da Família Real Portuguesa em 1808, e com a criação da primeira Constituição em 1824.

Gradativamente os livros chegavam ao Brasil e Oliveira (2004) destaca que já em 1837 o colégio Ginásio Nacional incluiu no seu currículo a disciplina de ginástica, que era um nome dado para a disciplina que viria a ser conhecida como educação física futuramente.

A visão da classe elitizada da época não valorizava atividades físicas. Para eles, como aponta Capraro e Souza (2017), as atividades físicas eram vistas como prejudiciais e entendidas como características de classes inferiores. Essa visão começou a mudar com o levantar de discursos pró-educação física obrigatória nas escolas vindas de homens influenciados por valores civis europeus, como Rui Barbosa, até que em 1879 o profissional de educação física consegue ter o mesmo reconhecimento que outros professores na escola por causa do decreto 7.247 de 19 de abril de 1879. Nesse momento, a disciplina passa a ter um valor de controle do corpo para mantê-lo saudável, robusto e harmonioso, além de proteção do corpo contra doenças. (CAPRARO; SOUZA, 2017).

Em 27 de Abril de 1932 a disciplina é regulamentada pelo ministro de Estado de Guerra do governo de Getúlio Vargas (Câmara, 2013). A constituição de 1937 apresenta a obrigatoriedade da disciplina de educação física através do artigo 131, ao declarar que:

A educação physica, o ensino civico e o de trabalhos manuaes serão obrigatorios em todas as escolas primarias, normaes e secundarias, não podendo nenhuma escola de qualquer desses gráos ser autorizada ou reconhecida sem que satisfaça aquela exigência. (BRASIL, 1937).

teórico-filosóficas para a construção de um projeto de reforma para educação brasileira. Após o retorno ao Brasil, Anísio Teixeira passou a desenvolver, gradativamente, com base no pragmatismo americano, uma concepção de educação escolar ampliada. (CAVALIERE, 2002). 
A educação física escolar era controlada pelo modelo da escola de educação física do exército. Do pensamento dos militares que comandavam essa escola é que saíam os parâmetros de atividades que seriam realizadas em todo o país e não de planejamentos exclusivos do Ministério da Educação, o que manteve a relação do exército com os educadores ainda mais difícil. O método utilizado por eles durou até a década de cinquenta. (OLIVEIRA, 2004).

Alguns anos depois, já na década de 1960, a educação física esteve presente na primeira versão da LDB (Lei de Diretrizes e Bases), que organiza e fixa os direcionamentos da educação nacional. Sendo assim, dentro da LDB, lei n. 4.024, de 20 de dezembro de 1961, no título V, art. 22 está escrito: Será obrigatória a prática da educação física nos cursos primários e médio, até a idade de 18 anos. Capraro e Souza (2017), afirmam que os ideais eugenistas e higienistas permaneceram ligados à disciplina de educação física durante o período militar dos anos 1960 e 1970, mas o principal fator era o nacionalismo. Castellani Filho (1998) pontua que a prática da educação física era desejada para capacitar fisicamente o trabalhador, e que na carta magna do Estado Novo aparecia o termo "adestramento físico", como objetivo dessa disciplina na escola. Castellani também apresenta o que poderia dispensar os alunos da disciplina: estar inserido no mercado de trabalho, ter mais de 30 anos de idade, estar prestando serviço militar ou ser fisicamente incapacitado; isso mostra que o pensamento era que a educação física não era necessária para alguém que já trabalha, pois se ele já consegue seus próprios recursos pode cuidar de si mesmo, ou para um homem mais velho, pois este já pode cuidar de si mesmo, ou mesmo para um militar, por este já fazer um trabalho equivalente fora da escola, e o incapaz (deficiente físico) estaria dispensado, pois o enfoque estava apenas em atividades físicas que ele não poderia realizar igual os outros.

Com a inserção do regime militar em 1964 aconteceram muitas mudanças na política brasileira. Algumas mudanças foram feitas, como uma modificação nos documentos vigentes na educação até então, e estão registradas em uma nova versão da LDB produzida em 1971. O documento apresenta na Lei n. 5.692, de 11 de agosto de 1971 no art. 7:

Será obrigatória a inclusão de Educação Moral e Cívica, Educação Física, Educação Artística e Programas de Saúde nos currículos plenos dos estabelecimentos de $1^{\circ} \mathrm{e}$ $2^{\circ}$ graus, observado quanto à primeira o disposto no Decreto-Lei n. 369, de 12 de setembro de 1969. (BRASIL, 1971).

Apesar do decreto 369, citado no artigo $7^{\circ}$, ressaltar a inclusão da educação moral e cívica, educação física e educação artística para a educação básica, o decreto 705, de 25 de julho de 1969 expande essa obrigatoriedade da educação física para o ensino superior como 
apresenta o texto no art. 1: "será obrigatória a prática da educação física em todos os níveis e ramos de escolarização, com predominância esportiva no ensino superior”. Esse texto ficou registrado como substituto do art. 22 de 1961 anteriormente apresentado.

De acordo com o diário oficial da união de 1997, após a LDB de 1996 a educação física se torna oficialmente uma disciplina facultativa, sendo a oferta da mesma uma proposta da instituição e não uma norma de um órgão superior; sendo assim, desde então as instituições poderiam escolher ou não ofertar essa disciplina. (BRASIL, 1997).

É possível organizar as principais datas envolvendo a disciplina de educação física na educação brasileira da seguinte forma:

- 1837 - O Colégio Nacional adiciona a disciplina de ginástica no currículo

- 1851 - Disciplina de ginástica é obrigatória nas escolas brasileiras

- 1879 - Decreto 7.247 - Reconhecimento do professor de educação física

- 1930 - Presidente Washington Luís encaminha projeto do Método Francês

- 1937 - Disciplina de educação física dentro das escolas

- 1961 - LDB, Lei N 4.024 - obrigatoriedade na educação básica

- 1969 - Decreto 705 - obrigatoriedade no ensino superior

- 1971 - LDB, Lei N 5.692 - permanece obrigatório na educação básica.

- 1996 - LDB, Lei Nº 9.394 - obrigatória para educação básica e o silêncio quanto ao ensino superior que será explicado em 1997

- 1997 - Documento oficial onde a educação física se torna facultativa.

A disciplina de educação física se estabeleceu na educação básica ao longo dos anos, mas com a não obrigatoriedade da disciplina de educação física no ensino superior em 1996, esta se tornou cada vez mais rara nas instituições de ensino superior brasileiras e continua a real questão de debate, se a educação integral tem acontecido com a ausência dessa disciplina no ensino superior.

Diante desse contexto o objetivo principal desse trabalho foi verificar como os aspectos do desenvolvimento físico estão sendo considerados no currículo do ensino superior de um Centro Universitário tri-campi no estado de São Paulo. 


\section{Método}

Foi realizada a análise das matrizes curriculares dos cursos de graduação no ensino superior adventista de São Paulo, verificando a presença de disciplinas relacionadas à atividade física após a implementação da lei $\mathrm{n}^{\circ}$ 9.394, de 20 de dezembro de 1996, que tornava a disciplina de educação física facultativa no ensino superior, através da verificação do nome da disciplina, posteriormente da ementa das disciplinas e em alguns casos também do plano de ensino, a fim de dirimir dúvidas. A consulta às matrizes foi realizada no site da IES, no período de outubro de 2016 a junho de 2017. Foram utilizadas matrizes anteriores e posteriores à revogação da obrigatoriedade, que estavam disponíveis no site e na secretaria da IES.

Esta pesquisa foi aprovada pelo comitê de ética do UNASP, sob número CAAE 66475717.9.0000.5377, e parecer 2.031.389, em 25 de abril de 2017.

\section{Resultados e discussão}

Ao analisar as matrizes curriculares do campus A, foi possível verificar que no ano de 1985 a matriz curricular do curso de Enfermagem possuía a disciplina de Educação Física (figura 1), assim como outros cursos de graduação, apenas no primeiro ano, mas dividida em 2 créditos por semestre: 
Figura 1 - Matriz Curricular de Enfermagem 1985

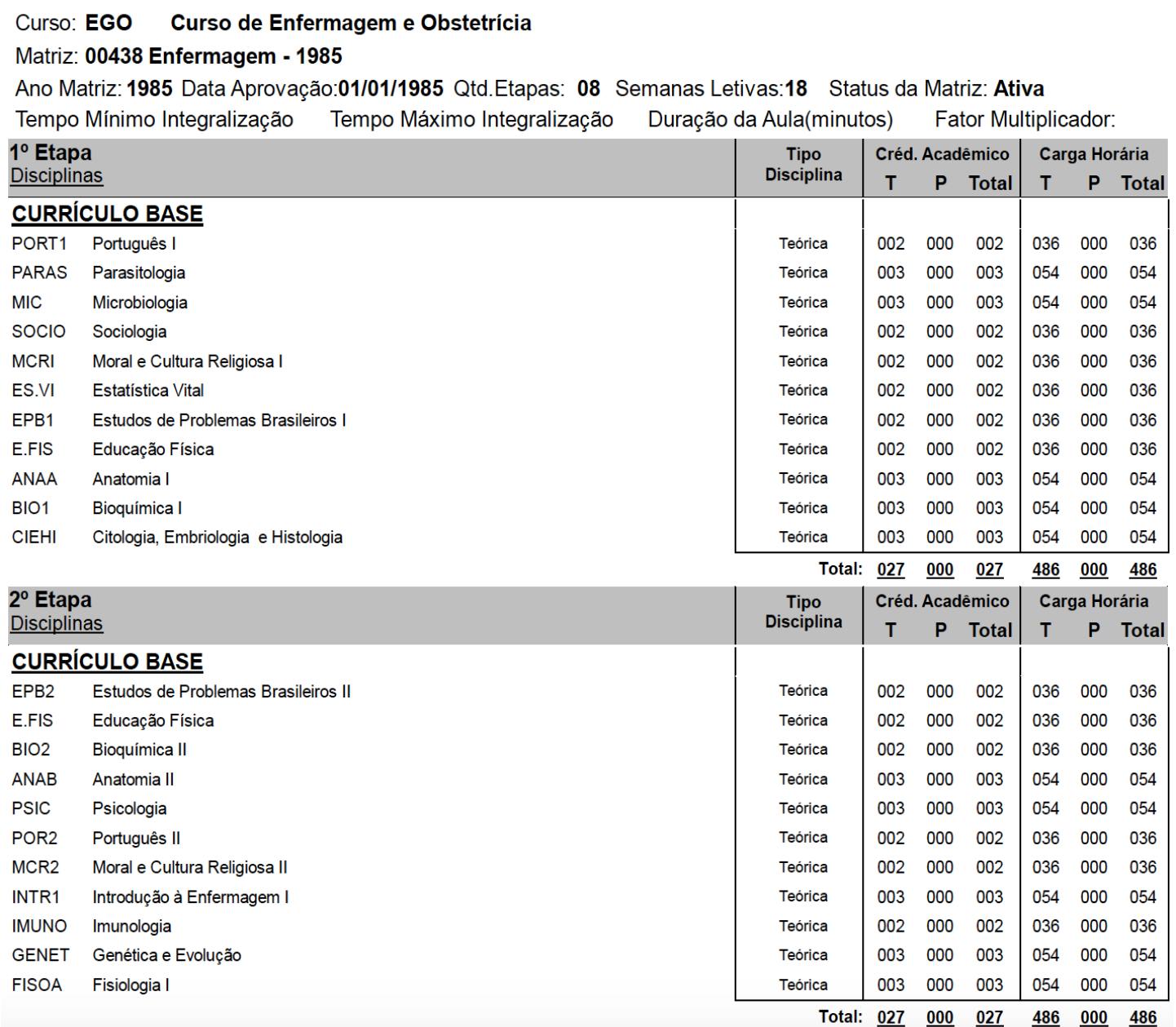

Fonte: Matriz Curricular (1985)

Analisando o currículo de enfermagem do ano de 1993 é possível verificar que a disciplina de educação física ganhou uma diferenciação por gênero, com educação física masculina e feminina e durando todo o primeiro ano de curso, como apresentado a seguir (figura 2): 
Figura 2 - Matriz Curricular de Enfermagem 1993

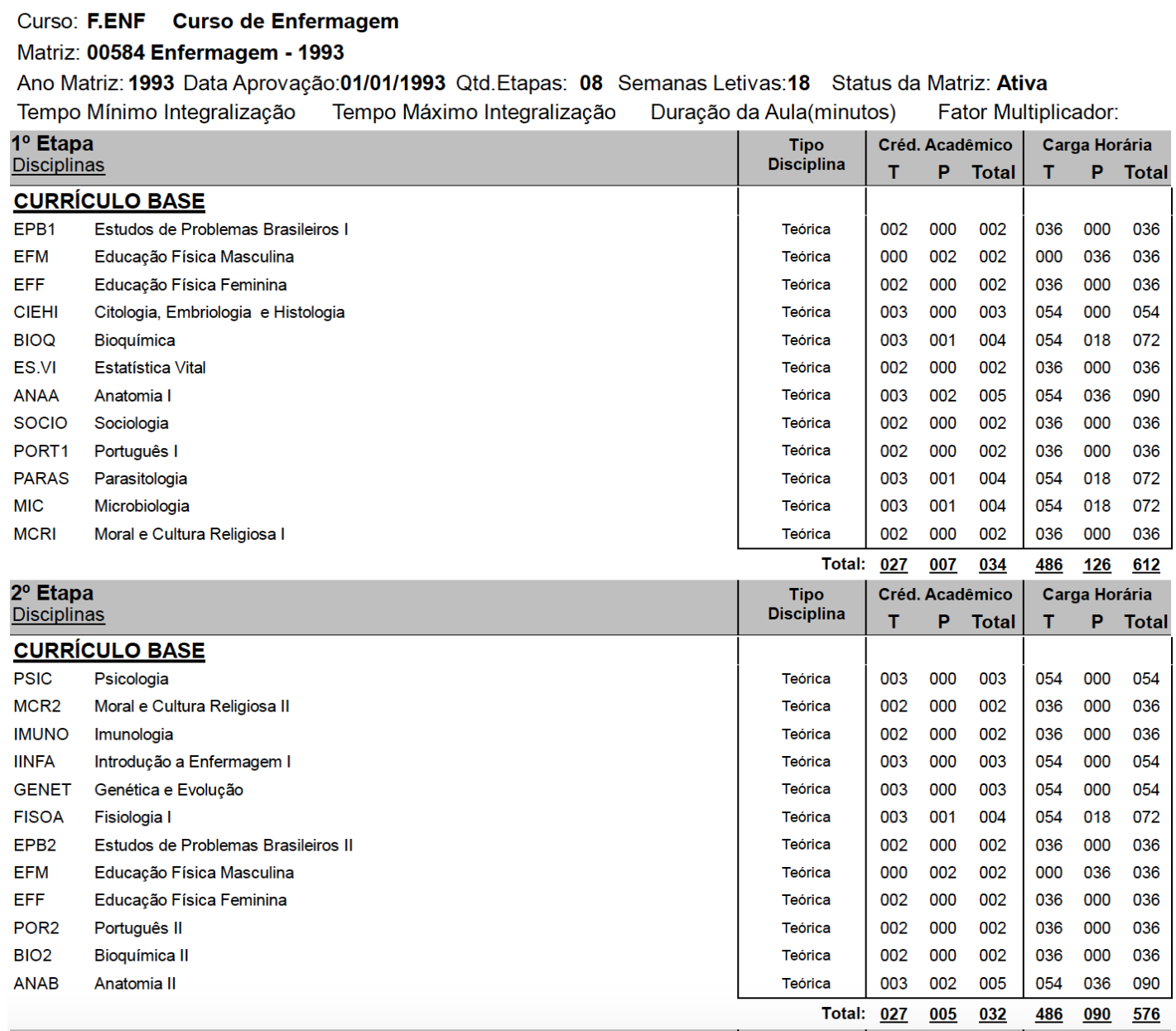

Fonte: Matriz Curricular (1993)

Ao analisar as matrizes curriculares de 1998, de três cursos que começaram suas atividades nesse mesmo ano, é visível que havia um consenso sobre a presença de disciplinas confessionais em cada semestre dos cursos, mas o mesmo não acontecia com a disciplina de educação física. O curso de Fisioterapia que estava iniciando suas atividades após ser autorizado pelo MEC já não possuía a disciplina de educação física em sua matriz, bem como o curso de matemática. Já o terceiro curso analisado, Ciências Biológicas, possuía a disciplina de educação física no primeiro e segundo semestre com dois créditos em cada.

Analisando a matriz de Nutrição do ano de 1999, as matrizes curriculares de Matemática e Ciência da Computação do ano 2000, e as matrizes de 2003 dos cursos de Sistemas para Internet e Pedagogia, visualiza-se que a disciplina de Educação Física já não está presente. Apesar da instituição ofertar o curso de Educação Física em dois de seus campi, a disciplina deixou de existir gradativamente nos demais cursos. 
Com os jovens trabalhando no período diurno, foram abertos cursos noturnos. Além dessa mudança do período de estudo, a duração de alguns cursos de licenciatura diminuiu de quatro para três anos, conforme resolução CNE/CP 2, de 19 de fevereiro de 2002 (BRASIL, 2002). Com essa mudança, o número de créditos e disciplinas foi reduzido para adequação dos cursos à nova realidade, e nessa redução de disciplinas a matéria de Educação Física saiu da matriz, o que foi acontecendo paulatinamente em cada campus.

Ao serem analisadas as matrizes curriculares posteriores a 2003 constatou-se que a partir desse ano não havia mais nenhuma disciplina diretamente relacionada à atividade física.

Todos os 32 cursos de graduação ofertados no ano de 2018 pelos três campi presenciais tiveram suas matrizes curriculares analisadas, e em nenhuma matriz, com exceção dos cursos de graduação Educação Física, há alguma disciplina atualmente ligada à atividade física. A disciplina atual mais próxima à área da educação física é a disciplina de Princípios de Vida Saudável, ofertada por um período apenas, no $5^{\circ}$ semestre contendo 2 créditos, em quase todos os cursos, exceto no curso de Publicidade e Rádio e TV que oferece essa disciplina no $3^{\circ}$ semestre. $\mathrm{O}$ curso de Ciências Biológicas possui uma disciplina denominada Ambiente e Saúde, no lugar da disciplina de Princípios de Vida Saudável. O curso de Teologia possui no primeiro ano a disciplina de Teologia e Princípios de Saúde, que tem o mesmo foco, e os cursos de Matemática e Tecnologia em Redes não possuem a disciplina de Princípios de Vida Saudável.

Em seguida foram analisados os planos de ensino da disciplina de Princípios de Vida Saudável que foi utilizada no ano de 2016 em três cursos diferentes, a saber: Pedagogia, Jornalismo e Direito. A análise feita não desmerece o trabalho dos professores conteudistas, apenas apresenta que a disciplina de Princípios de Vida Saudável não foi elaborada com o mesmo objetivo de uma disciplina de Educação Física, ambas são importantes e tem seus papéis.

No curso de pedagogia, a disciplina de Princípios de Vida Saudável possui apenas duas atividades em espaços diversificados, uma atividade no evento expo saúde, e outra na pesquisa de temas sobre os oito remédios naturais. Os conteúdos desenvolvidos em sala de aula foram: identificação do homem criado à imagem do Criador, saúde, célula, nutrientes como proteínas, carboidratos, lipídios, vitaminas e sais minerais, depois seminários sobre os remédios naturais e por fim doenças crônico degenerativas e a prevenção.

No curso de Jornalismo a disciplina de Princípios de Vida Saudável se apresenta ainda mais teórica do que em Pedagogia. Entre os conteúdos abordados estão o desenvolvimento biopsicossocial, bases da saúde e da doença, comportamentos saudáveis e os oito remédios 
naturais, princípios de vida saudável nos relacionamentos interpessoais e o relacionamento com Deus.

No curso de Direito, a disciplina em questão também se apresenta com muita teoria, abordando a temática do desenvolvimento integral, assim como os outros cursos fazem, mas assim como eles, o exercício em si também não é contemplado, visto que o enfoque está nas pesquisas e discussões sobre a importância do ser integral, o que leva o aluno a um melhor desenvolvimento cognitivo, mas não do físico. O exercitar e a parte prática poderia acontecer se a disciplina nesses cursos fosse mais voltada à atividade física e não apenas aos princípios teóricos de uma vida saudável.

A disciplina de Princípios de Vida Saudável se apresenta na matriz curricular como uma das disciplinas semestrais de cunho confessional dos cursos de graduação. Assim, como outras disciplinas confessionais e ligadas à área de estudo dos cursos, a disciplina de Princípios de Vida Saudável como apresentada nos planos de ensino é expositiva, com pouca participação ou envolvimento em atividades que tragam algum beneficio na prática para o corpo. Mas ainda que houvesse uma prática de atividade física nessa disciplina em busca do desenvolvimento integral do aluno envolvendo o aspecto físico, seria uma disciplina de 2 créditos em um único semestre em um contexto de um curso com em média de oito a dez semestres, sendo insuficiente para se caracterizar uma educação integral.

\section{Considerações finais}

Como analisado no capítulo ligado à matriz curricular, a disciplina de educação física deixou de ser obrigatória após a mudança feita pelo MEC em 1996 e saiu da matriz curricular da instituição pesquisada no início dos anos 2000, por adequação da carga horária dos cursos. A disciplina de educação física apresentava no plano de ensino mais atividades práticas com os alunos, diversidade de ambientes, como quadra e campo, visto que a ênfase é diferente da matéria de saúde atual.

Ao verificar possibilidades para contribuir para um melhor engajamento constante ao longo do ano letivo, no desenvolvimento físico, para trabalhar a educação integral na instituição, surgem ideias como a promoção dos esportes. Apesar de fazer parte do desenvolvimento físico, a atividade física dentro do pensamento da instituição não se resume apenas em esportes, uma aula de educação física ou um espaço ligado à atividade física dentro da instituição precisaria envolver tanto adeptos do esporte e outros que não o são, visto que de acordo com as pesquisas do DIESPORTE, excluindo os $46 \%$ da população brasileira que é 
sedentária, a fatia que se exercita está envolvida em sua maioria (29\%) com atividades físicas e 25,6\% com esportes, logo, a maioria prefere caminhada, academia ou outras atividades do que fazer esporte, então em um projeto para o ensino superior tanto sedentários quanto praticantes de atividades físicas e praticantes de esportes devem ser envolvidos.

Uma possibilidade seria a disciplina de Princípios de Vida Saudável, que já existe na matriz curricular, promover ações voltadas a práticas saudáveis para as turmas que não estão realizando esta disciplina no semestre. Dessa forma, o benefício se tornaria constante ao longo do ano e do curso, com o revezamento de turmas liderando os projetos para o ensino superior. Um projeto intercursos poderia ser feito semestralmente para atender todos os alunos dos campi. Esses alunos liderados por seus professores poderiam programar e oferecer atividades mensais aos alunos e comunidade, envolvendo atividades físicas e esportes, sendo seu ápice na semana de saúde, com palestras e atividades práticas como campeonatos intercursos e atividades afins com os alunos, comunidade e docentes da instituição.

Se atualmente o número de universitários sedentários tem aumentado, a reflexão sobre como fazer uma educação integral que envolva o aspecto físico se torna ainda mais relevante.

\section{REFERÊNCIAS}

BORTOLINI, R. W.; NUNES, C. A Paideia Grega: aproximações teóricas sobre o ideal de formação do homem grego. Rev. Filosofia e Educação, Campinas, v. 10, n. 1, p. 21-36, jan./abr. 2018.

BRASIL. Constituição de 10 de novembro de 1937. Disponível em: http://www2.camara.leg.br/legin/fed/consti/1930-1939/constituicao-35093-10-novembro1937-532849-publicacaooriginal-15246-pl.html. Acesso em: 15 nov. 2017.

BRASIL. [LDB (1971)]. Lei n 5.692, de 11 de agosto de 1971. Disponível em: http://www2.camara.leg.br/legin/fed/lei/1970-1979/lei-5692-11-agosto-1971-357752publicacaooriginal-1-pl.html. Acesso em: 15 nov. 2017.

BRASIL. MINISTÉRIO DO ESPORTE. DIESPORTE - Caderno 2. Diagnóstico Nacional do Esporte: O perfil do sujeito praticante ou não de esportes e atividades físicas da população brasileira. Disponível em: http://www.esporte.gov.br/diesporte/7.php. Acesso em: 05 dez. 2016.

BRASIL. Parecer 376/97, de 11 de junho de 1997. Lei de Diretrizes e Bases da Educação Nacional. Diário Oficial da União, Brasília, DF, 11 de junho de 1997. Disponível em: http://portal.mec.gov.br/cne/arquivos/pdf/1997/pces376_97.pdf. Acesso em: 16 out. 2017.

BRASIL. Resolução CNE/CP 2, de 19 de fevereiro de 2002. Conselho Nacional de Educação. Conselho Pleno. Diário Oficial da União, Brasília, DF, 04 de março de 2002. Disponível em: http://portal.mec.gov.br/cne/arquivos/pdf/CP022002.pdf. Acesso em: 6 nov. 2017. 
CÂMARA, R. H. Análise de conteúdo: da teoria à prática em pesquisas sociais aplicadas às organizações. Revista Interinstitucional de Psicologia, v. 6, n. 2; jul./dez., p. 179-191, 2013.

CAPRARO, A. M.; SOUZA, M. T. O. Educação física, esportes e corpo: uma viagem pela história [livro eletrônico]. Curitiba: Intersaberes, 2017.

CASTELLANI FILHO, L. Política educacional e educação física. Campinas, SP: Editora Autores Associados, 1998.

CAVALIERE, A. M. V. Educação integral: uma nova identidade para a escola brasileira? Educação Social, v. 23, n. 81, p. 247-270, Campinas, dez. 2002. Disponível em: http://www.scielo.br/pdf/es/v23n81/13940.pdf. Acesso em: 07 jun. 2018.

LORENZON, E. A.; JORGE, L. G. A. A ideia de Educação integral em Platão e Rousseau. Revista Perspectiva, Erechim, v. 35, n. 132, p. 7-17, dez. 2011.

NASCIMENTO, G. S.; SOUZA, M. E. S. Uma visão holística da educação: da fragmentação à totalidade. Revista Interletras, v. 3, n. 19, abr., set. 2014. Disponível em: http://www.unigran.br/interletras/ed_anteriores/n19/conteudo/artigos/19.pdf. Acesso em: 01 jun. 2018.

OLIVEIRA, V. M. O que é educação física. São Paulo: Brasiliense, 2004.

YUS, R. Educação Integral: uma educação holística para o século XXI. Porto Alegre: Artmed, 2002.

\section{Como referenciar este artigo}

SIMEON, Erling Walter Quiaper; VIANA, Helena Brandão. EDUCAÇÃO INTEGRAL NO ENSINO SUPERIOR: um olhar no aspecto físico. Revista Ibero-Americana de Estudos em Educação, Araraquara, v. 15, n. 1, p. 159-171, jan./mar. 2020. e-ISSN: 1982-5587. DOI: https://doi.org/10.21723/riaee.v15i1.12168

Submetido em: 31/01/2019

Revisões requeridas: $26 / 03 / 2019$

Aprovado em: 18/05/2019

Publicado em: 02/01/2020 